\title{
$\mathrm{Ni}$ 催化不对称氢化高效合成手性 2-噁唑烷酮
}

\author{
陈建中张万斌* \\ (上海交通大学化学化工学院＼cjkstart变革性分子前沿科学中心 上海市手性药物分子工程重点实验室 上海 200240)
}

\section{Efficient Synthesis of Chiral 2-Oxazolidinones via Ni-Catalyzed Asymmetric Hydrogenation}

\author{
Chen, Jianzhong Zhang, Wanbin* \\ (Shanghai Key Laboratory for Molecular Engineering of Chiral Drugs, Frontiers Science Center for Transformative Mole- \\ cules, School of Chemistry and Chemical Engineering, Shanghai Jiao Tong University, Shanghai 200240)
}

手性 2-噁唑烷酮及其衍生物不仅是一类非常重要 的手性辅剂(Evans 手性辅剂), 被广泛应用于构建各种 手性化合物, 而且还是一种重要的杂环结构单元, 广泛 存在于许多手性药物、天然产物和生物活性分子中. 目 前制备该手性 2-噁唑烷酮及其衍生物的常用方法是从 手性原料 $\beta$-氨基醇及其衍生物出发, 利用亲电性的 “ $\mathrm{C}=\mathrm{O}$ ” 试剂进行羰基化反应. 但该方法往往涉及到 使用光气及其衍生物、一氧化碳等剧毒和危险的羰基化 试剂或者使用二氧化碳等作为羰基来源在高温高压的 苛刻条件下反应.

不饱和杂环化合物的不对称氢化反应是合成手性 杂环化合物最高效的方法之一, 目前不对称氢化反应主 要是基于钉、铑、铱和钯等贵金属催化体系 ${ }^{[1]}$, 并且取 得了十分瞩目的成就, 但是这些贵金属存在着地球储量 稀少、价格昂贵、环境污染等问题. 因而, 发展地球储 量丰富、价格低廉、无毒或低毒的丰产金属铁、钴、镍 和铜的不对称氢化催化体系显得非常的重要, 也符合现 代化学可持续发展的要求. 镍是地壳中蕴藏量最丰富的 金属元素之一, 运用廉价易得的丰产金属镍进行催化不 对称氢化反应构建手性分子具有重要的研究意义, 因此 近年来备受人们的关注 ${ }^{[2]}$, 例如 Chirik、周建荣、张绪 穆和张万斌等课题组 ${ }^{[3]}$ 在该领域做了积极的探索, 并取 得了可喜的研究进展. 考虑到手性 4-取代-2-噁唑烷酮 杂环结构单元的重要性, 最近, 武汉大学化学与分子科 学学院董秀琴、张绪穆课题组 ${ }^{[4]}$ 实现了金属镍催化 2-噁 唑酮的不对称氢化反应, 为手性 2-噁唑烷酮类化合物的 制备提供了一种高效的合成途径(Scheme 1).

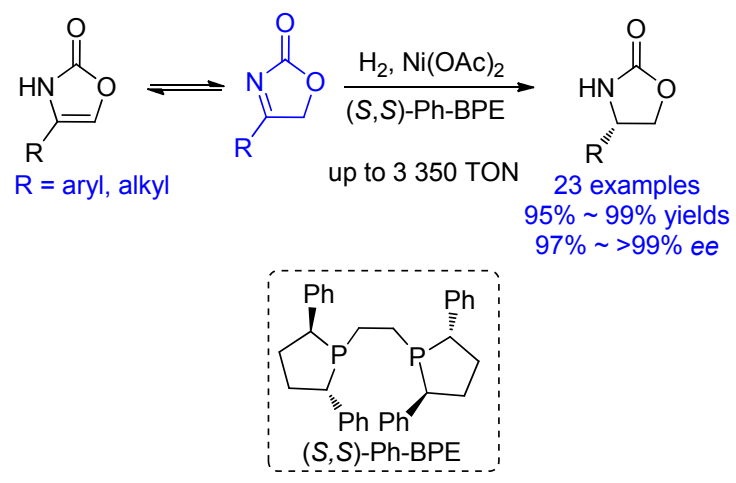

图式 $1 \mathrm{Ni}$ 催化的不对称氢化构建手性 2-噁唑烷酮 Scheme 1 Ni-catalyzed asymmetric hydrogenation to form chiral 2-oxazolidinones

经过条件篮选，作者找到了温和的不对称氢化反应 条件，进而对底物的适用范围进行了考察(表 1 ). 该氢 化反应体系对含有不同取代基的各种芳基底物具有良 好的兼容性，整体上取得了非常优异的对映选择性 $(99 \% \sim>99 \% e e)$. 另外, 作者进一步考察了具有挑战 性的烷基取代底物，也得到 95\%～98\%的产率和 97\% $>99 \%$ 的对映选择性.

为了探究该不对称氢化反应的机理，作者进行了一 系列的氛代实验和控制实验, 同时南京大学王敏燕对其 进行了密度泛函理论(DFT)理论计算, 提出了 Scheme 2 所示的机理. 该催化循环机理与反应的氢化结果和気代 实验结果是吻合的.

作者进而利用标准底物进行了克级规模的氢化反 应和高催化剂催化转化数(TON)实验, 使用 $0.02 \mathrm{~mol} \%$

\footnotetext{
* Corresponding author. E-mail: wanbin@sjtu.edu.cn. Published online December 4, 2020.
} 
图式 2 部分底物实例

Scheme 2 Partial examples of substrate<smiles>[R]c1coc(=O)[nH]1</smiles>
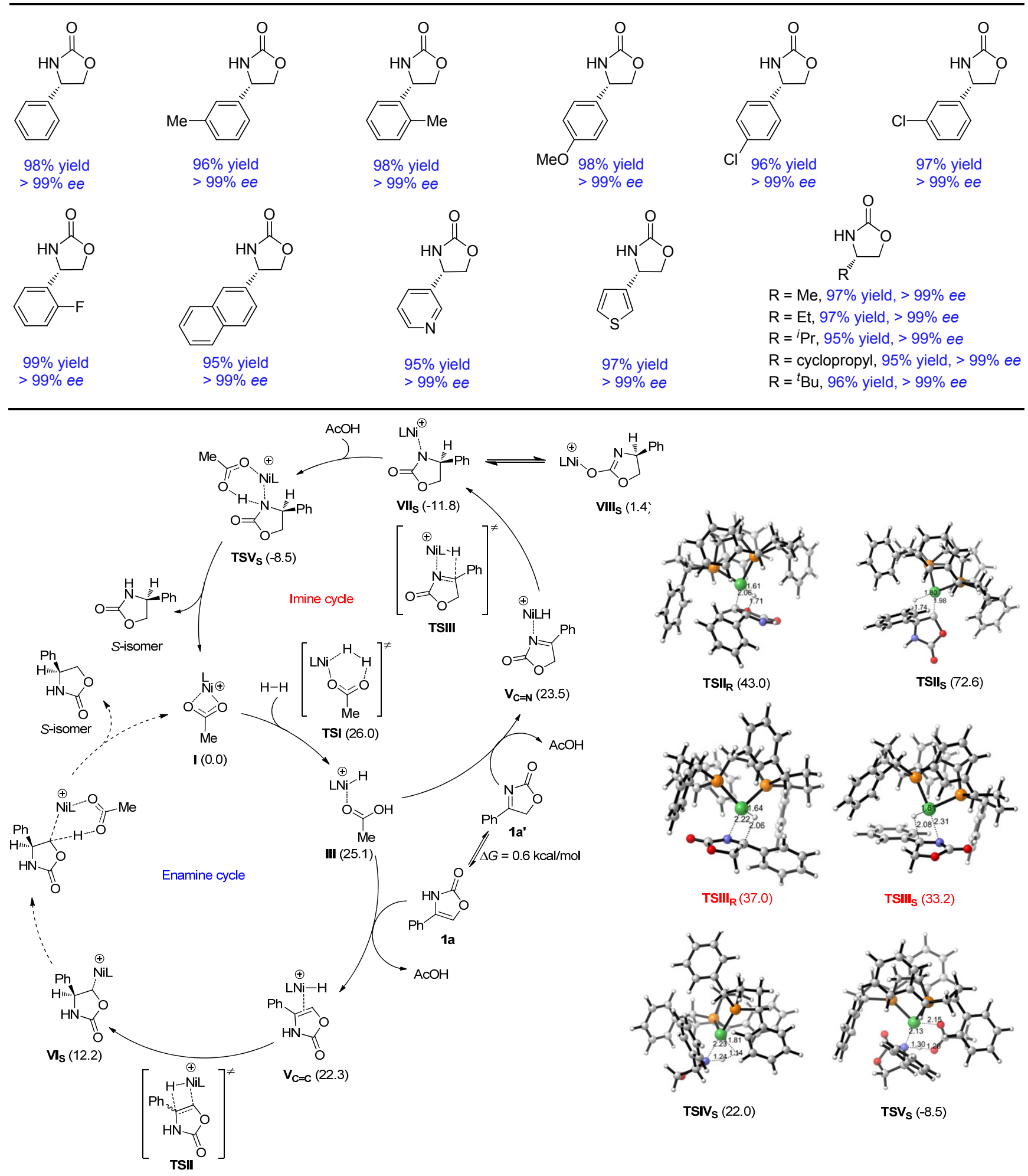

图式 3 可能的催化循环过程

Scheme 3 The proposed catalytic cycle 
催化剂用量时，以 $63 \%$ 分离产率和 $>99 \% e e$ 值得到氢化 产物, TON 高达 3350. 另外, 作者对氢化产物还进行了 一系列的合成转化, 充分显示出该方法具有比较高的合 成应用价值.

综上所述, 董秀琴、张绪穆课题组成功发展了金属 镍催化 2-噁唑酮的不对称氢化反应, 拥有非常宽的底物 普适性, 以高产率和优异的对映选择性得到在不对称合 成中应用广泛的手性 2-噁唑烷酮. 同时, 他们通过気代 实验、控制实验和 DFT 理论计算对该反应的催化机理 进行了研究.

\section{References}

[1] (a) Xie, J.-H.; Zhu, S.-F.; Zhou, Q.-L. Chem. Rev. 2011, 111, 1713 (b) Zhang, Z.; Butt, N. A.; Zhang, W. Chem. Rev. 2016, 116, 14769.
[2] Zhang, Z.; Butt, N. A.; Zhou, M.; Liu, D.; Zhang, W. Chin. J. Chem. 2018, 36, 443.

[3] (a) Shevlin, M.; Friedfeld, M. R.; Sheng, H.; Pierson, N. A.; Hoyt, J. M.; Campeau, L.; Chirik, P. J. J. Am. Chem. Soc. 2016, 138 , 3562 .

(b) Yang, P.; Lim, L. H.; Chuanprasit, P.; Hirao, H.; Zhou, J. Angew. Chem., Int. Ed. 2016, 55, 12083.

(c) Liu, Y.; Yi, Z.; Tan, X.; Dong, X.-Q.; Zhang, X. iScience 2019, 19,63 .

(d) Li, B.; Chen, J.; Zhang, Z.; Gridnev, I. D.; Zhang, W. Angew. Chem., Int. Ed. 2019, 58, 7329 .

(e) Hu, Y.; Chen, J.; Li, B.; Zhang, Z.; Gridnev, I. D.; Zhang, W. Angew. Chem., Int. Ed. 2020, 59, 5371.

(f) Liu, Y.; Dong, X.-Q.; Zhang, X. Chin. J. Org. Chem. 2020, 40, 1096 (in Chinese). (刘元华，董秀琴，张绪穆，有机化学, 2020, 40, 1096.)

[4] Liu, Y.; Yi, Z.; Yang, X.; Wang, H.; Yin, C.; Wang, M.; Dong, X.-Q.; Zhang, X. ACS Catal. 2020, 10, 11153.

(Cheng, F.) 